\title{
A Comparative Analysis on the Social Wellbeing of Adolescents with Parents in the Diaspora and those with Parents in the Home Country. A Case Study of Adolescents at Nemakonde High School: Mashonaland West Region, Zimbabwe
}

\author{
Pamela Chakombera $^{*}$, Augustine KudakwasheMubika ${ }^{2}$ \\ ${ }^{1}$ Midlands State University BSc Psychology Honors graduate \\ ${ }^{2}$ Senior lecturer: Zimbabwe Open University, Mashonaland West Region, P.O Box 285, Chinhoyi, Zimbabwe \\ *Corresponding Author: Pamela Chakombera, Midlands State University BSc Psychology Honors \\ graduate, Zimbabwe
}

\begin{abstract}
Separation of adolescents from their parents particularly caused by the diaspora syndrome has had negative implications on the social wellbeing of those adolescents left behind. This study attempts to find out whether there are significant differences in the social wellbeing for adolescents with parents abroad and the adolescents with parents in the home country; and use of the quantitative paradigm was found most appropriate. This is so because the quantitative paradigm is considered more efficient and it can be used to test hypothesis efficiently; hence the researchers found it suitable as it is relevant to the study's objectives. Unseeingly researchers also found it necessary to use the descriptive survey design. This design was found suitable because of its ability to provide frequencies and distributions of experiences and this enhances the readers' understanding of the subject-matter. The researchers drew a sample of 102 adolescents of which $50 \%(51)$ had parents in the home country and another 50\%(51) had parents in the diaspora. The stratified sampling and the simple random sampling techniques were used. Inferential and descriptive statistics were thus used for data analysis. The study findings suggest that there are significant differences in the social wellbeing of the adolescents with parents in the home country and adolescents with parents in the diaspora. The study recommends that more research be carried out as there is dearth in the literature regarding migration and generally families left behind in Zimbabwe.
\end{abstract}

\section{BACKGROUND}

External migration also known as international migration is very common in developing countries worldwide where citizens leave their home countries to go to other countries. In most cases parents leave their children behind due to many factors for instance some migrants enter the receiving country illegally and taking children along can be risky, there may be difficulties in receiving countries, temporary migration, unfavorable immigration policies in the receiving countries among others (Bălţătescu, Hatos\&Oşvat 2014). Out migration is considered voluntary or involuntary on the parent's side. According to Flahaux and De Haas (2016) the African continent is regarded to be with the most mobile populaces in the world, it is stereotyped to be a continent on the move. Out-migration is also prominent in the Caribbean islands of America in countries like Guyana, Haiti, Jamaica among other countries. Most studies have been carried out in these countries on the effects of migration on children as well as families left behind. Crawford-Brown (1994) in a study in Jamaica coined the word 'barrel children' to refer to Jamaican children deprived of their parents and are products of what is termed 'stepwise migration'.

Out-migration of this nature is due to several factors which include socio-economic challenges, job searches and better learning conditions. The adoption of the United States dollar by Zimbabwe government in 2009 has not done much to eradicate the socio-economic challenges that are prominent in the country of study, Zimbabwe. Thus, the number of people migrating from Zimbabwe has not decreased. Zimbabwe's economic empowerment policies do not attract foreign investments, and this has resulted in the dilapidation of the country's economy resulting in national unemployment. Studies on the effects of parental international migration on adolescents have been carried out in Beitbridge and Shashe; southern part of Zimbabwe. Adolescents might find it difficult to cope with the 
A Comparative Analysis on the Social Wellbeing of Adolescents with Parents in the Diaspora and those with Parents in the Home Country. A Case Study of Adolescents at Nemakonde High School: Mashonaland West Region, Zimbabwe

transitions that come along with this stage of life. This age group is distinct in its own ways. Adolescents need the psychological help of parents and others to cope with the various changes that occur at this stage of life. Given this it becomes apparently clear that in the absence of parents, problems affecting the adolescents left behind by their parents would negatively affect the adolescents' social wellbeing.

\section{Statement Of The Problem}

In recent years there has been some disturbing increase in the rate of emigration of Zimbabwean citizens to other countries leaving their adolescents behind. The absence of parents has created serious social problems on the adolescents left behind. This has clearly created differences between adolescents with parents in the home country and those with parents in the diaspora. That being the case it has become necessary for the researchers to consider whether there are any significant differences in the social wellbeing for adolescents with parents in the diaspora and those with parents in the home country.

\subsection{Purpose of the Study}

Based on the above discussion the purpose of the study is to find out whether there are any differences in the social wellbeing for adolescents with parents in the home country and those within the home country with reference to adolescent sat Nemakonde High School in Mashonaland West Province: Zimbabwe.

\section{Research Questions}

In an effort to respond to the main problem the study attempted to answer the following research questions:

1. Are there any significant differences in social integration for adolescents with parents in the diaspora and those with parents in the home country?

2. Are there any significant differences in social acceptance for adolescents with parents in the diaspora and those with parents in the home country?

3. Are there any significant differences in social contribution for adolescents with parents in the diaspora and those with parents in the home country?

4. Are there any significant differences in social actualization for adolescents with parents in the diaspora and those with parents in the home country?

5. Are there any significant differences in social coherence for adolescents with parents in the diaspora and those with parents in the home country?

\subsection{Significance of the Study}

The study is likely to help adolescents develop an understanding that absence of parents at times is not by choice and as such they should not live their lives blaming their parents for every experience they encounter. The study is likely to provide adolescents with a platform to self-evaluate and appreciate absence of parents as a measure central to personal growth and use of independence responsibly, it is the foundation to the development of individual maturity.

This research is likely to help parents understand the importance of their presence in the children's lives and how it interacts with adolescents' emotional, psychological, social and behavioral development. The research is likely to help parents appreciate that frequent contact with children is significant for esteem, confidence, self-worth and efficacy of adolescents. The study is likely to develop a platform for further research into social experiences of adolescents with parents who live in the diaspora. The research will also add to the board of literature on the experiences of adolescents as well as strategies to enhance their social well-being.

\section{REVIEW OF RELATED LiTERATURE}

\subsection{International migration}

This refers to the movement of people from one country to other countries, in search of opportunities to better their lives, seek political refugee, further one's studies, gain new experiences, and flee from disaster and famines among others. This is a political, economic as well as a social process that has an 
A Comparative Analysis on the Social Wellbeing of Adolescents with Parents in the Diaspora and those with Parents in the Home Country. A Case Study of Adolescents at Nemakonde High School: Mashonaland West Region, Zimbabwe

impact on the source and receiving countries. Globalization has contributed to the rise of migration in the world as people worldwide can now easily connect. Zimbabwe National Statistics Agency (ZIMSTAT) in 2014 assert that $43.9 \%$ of Zimbabweans emigrated due to the lack of job opportunities, whilst $18.3 \%$ migrated in the quest to increase household income. Illegal migration is very common in Zimbabwe and in most cases the migrants would be migrating to countries in southern Africa. The organization (ZIMSTAT, 2014) posits that $85.7 \%$ of Zimbabwean emigrants would be migrating to South Africa and among them are illegal migrants. Dube (2014) in a study in the southern part of Zimbabwe found that most of these illegal emigrants leave children behind because they consider the process of illegal migration dangerous and they cannot risk their children's lives. According to (ZIMSTAT, 2014) the organization revealed that 53\% of out-going, $41.9 \%$ labor migrants had left children, adolescents included, behind in the home country Zimbabwe.

Africa has been tagged one of the world's regions with the highest migrating populaces and this has been mainly attributed to socio-economic challenges and political instability among others. Africans in east and north Africa usually migrate to countries in Europe. In most instances the Africans migrate to nations that once colonized them. The Caribbean islands of America, South America, India and China are some of the regions in the world with high levels of emigration.

International migration poses certain problems to both the receiving and sending nations.

\subsection{Social integration}

Social integration is the assessment of worthiness of an individual's interactions with others in the society (Keyes, 1998). Keyes (1998) further asserts that social integration is the degree to which an individual feels they have a common ground with people who constitute the individuals' social reality. Therefore, one may posit that a healthy adolescent has a sense of belongingness to the society. Wilkinson (2004) asserts that the nature of relationship an adolescent has with their parents influences the attitude they will have toward themselves and towards their peers. Thus, parental presence and absence can have a negative or positive implication on the social integration aspect of social wellbeing of the adolescents left behind. Lam (2013) asserts that children left behind by migrant parents often feel lonely and isolate themselves from other children and the society. In line with the argument Cappelloni (2011) also offer supportive evidence that stepwise children feel rejected and in most instances withdraw themselves from the society. Hoang (2015) states that this withdrawal is a result of lack of emotional support from significant others in the society. According to Kufakurinani, Pasura and McGregor (2014) there are communication difficulties between parents and 'diaspora orphans" who are the children left behind especially parents who would have crossed regional boarders as they cannot afford the telephone charges. They further postulate that these children are stigmatized and are often associated with socially unacceptable behaviours, this is mainly attributed to the fact that they do not have role models.

\subsection{Social acceptance}

Keyes (1998) posits that social acceptance is an indicator of good mental health, social acceptance is when adolescents in the quest to fit in the society try to look and act like other people in the society. Adolescents who are socially accepted trust others and hold the human side rather than the logic side when dealing with other people. Adolescents left behind are forced to bank their trust on other that are not their parents because they are left in the care of those people. In most cases these children move from one relative to the other creating more relationships that need to be built on trust. Cortes (2007) posits that FLACSO in a study in Ecuador found that left behind children share undesirable perceptions of their parents and themselves. Wilkinson (2004) asserts that prolonged separation of children from their parents can result in anger and create trust issues in the adolescents. Promises made by parents to reunite with their children that are not fulfilled tend to result in emotional instability in the adolescents, and this can have a negative implication on the social aspect of social wellbeing of the adolescents left behind.

\subsection{Social contribution}

Keyes (1998) defines social contribution as an assessment of an individual's social value. An adolescent view of herself or himself as an important member of the society. The adolescent takes 
A Comparative Analysis on the Social Wellbeing of Adolescents with Parents in the Diaspora and those with Parents in the Home Country. A Case Study of Adolescents at Nemakonde High School: Mashonaland West Region, Zimbabwe

responsibility of his or her actions as they are significant to the society. Keyes (1998) asserts that responsibility and self-efficacy are key elements in social contribution. Social contribution is also considered to have a close relationship with motives and behaviors. Adolescents left behind by migrant parents end up taking parental roles which are supposed to be done by their parents 'parentification'. The act of doing so illustrates a positive social contribution as the adolescents take responsibility of social duties and roles. Kufakurinani, Pasura and McGregor (2014) suggest otherwise; they posit that these adolescents are often associated with delinquent behavior and are reckless with their lives. Moctezuma (in Cortez 2007) findings in a study in Mexico suggest that 'stepwise' adolescent children would end up being labour migrants. This is attributed to the fact that adolescents view migration as a way out of poverty. Reports in Moldova suggest that academic performance of children left behind is often affected by the increase in household responsibilities and duties to take care of younger siblings (UNICEF, 2006). Meyerhoefer and Chen (2011) findings in China suggest that the girl child education experience a drawback due to the shifting allocation of time towards home production. Teachers in Beitbridge established that in the case that both parents migrated leaving adolescents behind, in most instances these adolescents would head the remaining families. A study carried out established that about $60 \%$ of Shashe Secondary School pupils in Beitbridge headed the remaining families (Dube, 2014).

\subsection{Social actualization}

Social actualization is the assessment of the potential of the society in which the adolescent is part of, it mainly focuses on growth and development (Keyes, 1998). Adolescents with a higher social wellbeing hold the conviction that they and other people in the society are direct beneficiaries of the society. Social actualization posits that it is the society itself that can control its destiny (Keyes, 1998). Education is then an important element in social actualization. Dube (2014) postulates that one of the negative effects of parental migration on left behind children manifests on the academic performance of the adolescents. The adolescents are demotivated to do their school work, expecting to migrate themselves. Studies in Beitbridge Zimbabwe indicate that migration creates a negative deceptive perception on the adolescents when migrants returned home with materials (Dube, 2014). Adolescents perceive migration as better compared to education. Most of the migrants do not have any educational qualification yet they return home with materials that even the educated in Zimbabwe cannot afford. These behaviors pose a threat to the social actualization aspect of social wellbeing of the adolescents.

\subsection{Social coherence}

Social coherence is considered as the view of the worthiness, level of organization and operations in a society (Keyes, 1998). Socially healthy adolescents understand the society they are living in. In the context of Zimbabwe, adolescents understand the economic situation and what prompted their parents to migrate. Keyes (1998) asserts that healthier adolescents view their lives as meaningful and comprehensible.

Cortes (2008) in Moldova revealed that children left behind suffer from neglect, this neglect is in different forms ranging from food, clothes, medical, educational and affectionate. This then negatively affects the adolescents emotionally and socially. This can manifest in the adolescent's life in the form of low self-esteem, lack of long term goals and sensible aspirations. Xinlu (2014) posits that suicidal tendencies are common in adolescents left behind by migrant parents. The adolescents are in most cases not prepared to face their separation from the parents. The reason for taking this move is because they are not prepared to face the feeling of abandonment, punishment, failure in their academic work and the likes. Reports in Romania state that between the years 2006-2009 at least 14 children left behind committed suicide (Bilefsky, 2009). Hetherington \& Martin (1979) quoted by Bates, Maslin and Franke (1985) offer suggestive evidence that male and female adolescents with absent fathers often find it difficult to be patient. The adolescents are also characterized by being impulsive and as a result are often impulsive and lack control. These adolescents indulge in sexual activities at an early age than adolescents with parent in the home country.

\section{SOCIAL IDENTITY THEORY}

Basing on Tajfel social identity theory, the groups in which adolescents belong to are their source of pride and esteem. These groups that can either be social class, family, barrel children, school institute 
A Comparative Analysis on the Social Wellbeing of Adolescents with Parents in the Diaspora and those with Parents in the Home Country. A Case Study of Adolescents at Nemakonde High School: Mashonaland West Region, Zimbabwe

or the like give adolescents a sense of social identity. For the adolescents to increase their self-image they must enrich the status of their group. Adolescents left behind by migrant parents often withdraw from other children and discriminate other adolescents with parents in the home country. They do so in a quest to increase their self-image. In most cases they identify themselves with the countries their parents migrated to. This is seen in most cases with their dressing that identifies with the countries that their parents migrated to.The adolescents define appropriate behaviours in terms of the norms of the group they belong to. In most cases the social behaviour of the adolescents left behind is the same since they adhere to the same norms. In the case that an adolescent identifies himself/herself as a barrel child he/she is likely to act in a manner that barrel children act. This then result in social comparison whereby the adolescents start to compare themselves with other groups; in this case it might be with the group of adolescents with parents in the home country. Over appreciation and under appreciation is common at this stage of the adolescent's lives.

\subsection{Research methodology}

The research chose the quantitative research paradigm and adopted the descriptive survey design. Quantitative research paradigm is efficient and can test hypothesis thus the researchers found it suitable because it suits objectives of this study. The descriptive survey design was used because it provides frequencies and distributions of experiences in the manner that readers can easily understand. The study sought to find if there are any significant differences in the social wellbeing of adolescents with parents in the diaspora and those with parents in the home country. To solicit data from the potential respondents the questionnaire, scheduled interviews and documentary analysis were used. The use of the three data collection methods enabled the researchers to cross validate the data and this helped to boost data validity and reliability.

\subsection{Target Population}

The population of the study was made up of 270 adolescent students from form one to form four at Nemakonde High School in Chinhoyi town in Makonde District of Mashonaland West Province in Zimbabwe. This target population had some students with parents in the diaspora while other students had parents in the home country.

\subsection{Sample and sampling procedure}

Out of a total population of 270 only 102 made it into the sample that was chosen through random and use of random sampling technique. Of the 102 adolescents 50\% (i.e. 51 adolescents) had parents in the diaspora and the other $50 \%$ (i.e.51 adolescents) had parents in the home country. The sample size constitutes $37,78 \%$ of the population which is representative enough to make inferences about the whole population of the study. The researchers drew the sample of 102 individual adolescents with guidance of the Shakaran table for determining sample sizes $51(50 \%$ of the sample) adolescents with parents in the home country and these represented the control group. The other $51(50 \%$ of the sample) adolescents with parents in the diaspora and those represented the experimental group. The sample size was drawn at confidence level $95 \%$ and a degree of accuracy 0.05 (as recommended by the American Psychology Association).

\section{DATA COLleCtion InSTRUMENTS}

The researchers used the questionnaire as the main research data collection instrument. The data collected were based on objectives of the study. The reliability co-efficient of the six subscales (social integration, acceptance,contribution, actualization,coherence) is above .70 . The respondents indicated their level of agreement or disagreement to the provided questions on the questionnaire. The researchers chose the questionnaire for it best suits quantitative research and it is objective in nature ensuring reliability of the test results. All sections contained questions on a six unidirectional Likert scale. The respondents indicated their level of agreement or disagreement to the provided questions on the questionnaire. The researchers had also earlier on conducted a feasibility study on 20 high school students at Chinhoyi High School Number 2 in Chinhoyi with similar characteristics to those of the intended population. This was to see if the questionnaire designed and the sub sections on it were clear to the participants. The pre-testing procedure was also an approximate of the original research 
A Comparative Analysis on the Social Wellbeing of Adolescents with Parents in the Diaspora and those with Parents in the Home Country. A Case Study of Adolescents at Nemakonde High School: Mashonaland West Region, Zimbabwe

methodology to assess the validity and reliability of the approach to research. The researchers from this pre-test identified that the Cronbach alpha of the instrument was slightly high ranking at significant level .784, and this signified that the instrument was reliable and valid in assessing what it was intended to measure. The data collected in the research were analyzed using the Statistical Package for the Social Sciences (SPSS) version 16.1. Data collected in the field was assessed using a wide range of statistical procedures. Both inferential and descriptive statistics where used to analyze and present the findings. The data were analyzed using T-Test that tested for significant differences between the two populations that where being assessed for their social experiences and how they affect the wellbeing of these students. To further justify our t-test a pretest was carried out and data were drawn from a normally distributed population and interval data were used in the study. The t-test was chosen as it tests for differences between two independent samples.

Table1. T-test for equality of means (social wellbeing)

\begin{tabular}{|c|c|c|c|c|c|c|c|c|c|c|}
\hline \multicolumn{11}{|c|}{ Independent Samples Test } \\
\hline & & \multicolumn{2}{|c|}{$\begin{array}{l}\text { Levene's Test } \\
\text { for Equality of } \\
\text { Variances }\end{array}$} & \multicolumn{4}{|c|}{ T-test for Equality of Means } & & & \\
\hline & & \multirow[t]{3}{*}{$\mathrm{F}$} & \multirow[t]{3}{*}{ Sig. } & \multirow[t]{3}{*}{$\mathrm{t}$} & \multirow[t]{3}{*}{ df } & \multirow{3}{*}{$\begin{array}{l}\text { Sig. (2- } \\
\text { tailed) }\end{array}$} & \multirow{3}{*}{$\begin{array}{l}\text { Mean } \\
\text { Difference }\end{array}$} & \multicolumn{3}{|c|}{ Std. $\quad$ Error $95 \%$} \\
\hline & & & & & & & & \multirow[t]{2}{*}{ Difference } & \multicolumn{2}{|c|}{$\begin{array}{l}\text { Confidence } \\
\text { Interval of the } \\
\text { Difference }\end{array}$} \\
\hline & & & & & & & & & Lower & Upper \\
\hline \multirow[t]{2}{*}{ Relations } & $\begin{array}{|ll|}\text { Equal } & \text { variances } \\
\text { assumed } & \end{array}$ & 4.346 & .038 & -1.031 & 194 & .304 & -.011 & .010 & -.031 & .010 \\
\hline & \begin{tabular}{|l|} 
Equal variances \\
not assumed
\end{tabular} & & & -1.000 & 94.000 & .320 & -.011 & .011 & -.031 & .010 \\
\hline \multirow[t]{2}{*}{ Communicatior } & $\begin{array}{l}\text { Equal variances } \\
\text { assumed }\end{array}$ & 4.346 & .038 & -1.031 & 194 & .304 & -.011 & .010 & -.031 & .010 \\
\hline & \begin{tabular}{|l|} 
Equal variances \\
not assumed
\end{tabular} & & & -1.000 & 94.000 & .320 & -.011 & .011 & -.031 & .010 \\
\hline \multirow[t]{2}{*}{ Trust } & $\begin{array}{|ll|}\text { Equal variances } \\
\text { assumed }\end{array}$ & 4.346 & .038 & -1.031 & 194 & .304 & -.011 & .010 & -.031 & .010 \\
\hline & \begin{tabular}{|l|} 
Equal variances \\
not assumed
\end{tabular} & & & -1.000 & 94.000 & .320 & -.011 & .011 & -.031 & .010 \\
\hline \multirow[t]{2}{*}{ Behavior } & \begin{tabular}{|l|}
$\begin{array}{l}\text { Equal variances } \\
\text { assumed }\end{array}$ \\
\end{tabular} & 1.088 & .298 & -.520 & 194 & .603 & -.012 & .023 & -.056 & .033 \\
\hline & \begin{tabular}{|l|} 
Equal variances \\
not assumed
\end{tabular} & & & -.517 & 179.547 & .606 & -.012 & .023 & -.057 & .033 \\
\hline \multirow[t]{2}{*}{\begin{tabular}{|l|} 
social \\
wellbeing
\end{tabular}} & $\begin{array}{|ll|}\begin{array}{l}\text { Equal variances } \\
\text { assumed }\end{array} & \\
\end{array}$ & 21.802 & .000 & 42.490 & 194 & .000 & .950 & .022 & .906 & .995 \\
\hline & $\begin{array}{l}\begin{array}{l}\text { Equal variances } \\
\text { not assumed }\end{array} \\
\end{array}$ & & & 43.818 & 100.000 & .000 & .950 & .022 & .907 & .994 \\
\hline
\end{tabular}

Table1: Illustrating that there are no significant differences in terms of the sub dimensions of social wellbeing relation, communication, trust and behavior. This is indicated by the $.304, .304, .304, .603$ respectively significant levels of the sub dimensions of social wellbeing. This shows that parental absence or presence has no influence on the sub dimensions of social wellbeing of the adolescents. The table also shows that there are significant differences in terms of the overall social wellbeing of adolescents whose parents are in the diaspora and those with parents in the home country. This is indicated by the .000 significant level. This then implies that there are significant differences between the two groups as illustrated by the $t$ test. Therefore, parental presence and absence has an influence on the overall wellbeing of the adolescents.

\section{Discussion OF RESUlts}

The research findings suggest that there are no significant differences in the sub-dimensions of social wellbeing of the adolescents but there are significant differences in the overall social wellbeing. The sub-dimensions relations, communication, trust and behaviour showed no significant differences between the two groups. Hoang (2015) asserts that adolescents with parents abroad often withdraw from the society resulting in negative relations with others. The results of the study indicate otherwise as they show that there are no differences with their counterparts meaning there is no difference in 
A Comparative Analysis on the Social Wellbeing of Adolescents with Parents in the Diaspora and those with Parents in the Home Country. A Case Study of Adolescents at Nemakonde High School: Mashonaland West Region, Zimbabwe

terms of social integration. The study indicates that there are no significant differences in terms of trust between the two groups. Cortes (2008) asserts that parental separation with the adolescents creates trust issues in the adolescents. The results of the study however indicate that there are no differences with the other adolescents showing that there is less gravity of the parental absence influence on the adolescent's trust meaning there is no difference in terms of social acceptance. The results of the study indicate that there is no difference in terms of the social wellbeing sub dimension behavior. Crawford-Brown (1999) suggests that mother's absence is a contributing factor to violent behaviors of the adolescents left behind. The results of the study show that there are no significant differences in terms of behavior of the two groups. Therefore, there is no significant difference in terms of social contribution of the adolescents as indicated by the study. The (UNICEF, 2011) in a study in Tajikistan offer qualitative and quantitative evidence that family disintegration and parental deprivation as a cause of parental migration has negative social cost on the children left behind. This then negatively affects the social wellbeing of the adolescents left behind. The study shows that there are significant differences in terms of the overall social wellbeing.

\section{CONCLUSiONS}

The following conclusions were drawn from the above discussions:

1. There are no significant differences in terms of social integration for adolescents with parents in the diaspora and those with parents in the home country.

2. There are no significant differences in terms of social acceptance for adolescents with parents in the diaspora and those with parents in the home country.

3. There are no significant differences in terms of social contribution for adolescents with parents in the diaspora and those with parents in the home country.

4. There are no significant differences in terms of social actualization for adolescents with parents in the diaspora and those with parents in the home country.

5. There are no significant differences in terms of social coherence for adolescents with parents in the diaspora and those with parents in the home country.

Finally, this study concludes that there are significant differences in the social wellbeing for adolescents with parents in diaspora and those with parents in the home country. The research findings indicate a poor overall social wellbeing on adolescents with parents abroad (diaspora) as compared to adolescents with parents in the home country.

\section{RECOMMENDATIONS}

Based on the above conclusions, the study recommends that;

1. Government comes up with implementable policies that ensure that adolescents with parents in the diaspora are, through practical socio-economic projects/programs, integrated so that they become part and parcel thereby enhancing their integration into the entire societal life.

2. Policies making it possible for adolescents with parents in the diaspora to be socially accepted by the society are place. The government should introduce social interventions that can help the adolescents regain trust.

3. Government ensures that the legal framework allows adolescents with parents in the diaspora to meaningfully contribute in societal projects and programs.

4. Government ensures through appropriate statutory instruments that adolescents with parents in the diaspora are not demotivated but instead are encouraged and helped to realize their full potential to bring about meaningful self-actualization.

5. Mechanisms must be put in place that help adolescents understand the society they live infor them to meaningfully adhere to it.

\section{REFERENCES}

[1] Bălţătescu, S., Hatos, A., \&Oșvat, C. The effects of parental migration on subjective well-being of children: the case of Romania.

[2] Bates, J. E., Maslin, C. A., \& Frankel, K. A. (1985). Attachment security, mother-child intemraction, and 
A Comparative Analysis on the Social Wellbeing of Adolescents with Parents in the Diaspora and those with Parents in the Home Country. A Case Study of Adolescents at Nemakonde High School: Mashonaland West Region, Zimbabwe

temperament as predictors of behavior-problem ratings at age three years. Monographs of the society for research in child development

[3] Bilefsky, D. (2009). In Romania, children left behind suffer the strains of migration. New York Times.

[4] Cappelloni, C. (2011). Going Beyond Material Well-Being: Looking at the Hidden Costs of Migration on Children Left Behind. Fletcher J. Hum. Secure., 26, 24-37.

[5] Crawford-Brown, C., \& Rattray, M. (1994). The "barrel children" of the Caribbean: The socio-cultural context of the migrant Caribbean family. Department of Sociology and Social Work, UWI, Mona, Jamaica ISER.

[6] Crawford-Brown, C. (1999). The impact of parenting on conduct disorder in Jamaican male adolescents. Adolescence, 34(134), 41

[7] Cortes, R. (2007). Global report on migration and children. Children and women left behind in labour sending countries: an appraisal of social risks.

[8] Cortes, R. (2008). Children and Women Left Behind in labour sending countries: an appraisal of social risks. New York: United Nations Children's Fund (UNICEF), Policy, Advocacy and Knowledge Management Section, Division of Policy and Practice.

[9] Dube, T. (2014). The Socio-Economic Effects of Cross-Border Migration on Zimbabwe's Border Lying Communities-A Case Study of Beitbridge and Plum tree.

[10] Hoang, L. A., Lam, T., Yeoh, B. S., \& Graham, E. (2015). Transnational migration, changing care arrangements and left-behind children's responses in South-east Asia. Children's geographies, 13(3), 263277.

[11] Keyes, C. L. M. (1998). Social well-being. Social psychology quarterly, 121-140.

[12] Flahaux, M. L., \& De Haas, H. (2016). African migration: trends, patterns, drivers. Comparative Migration Studies, 4(1), 1.

[13] Kufakurinani, U., Pasura, D., \& McGregor, J. (2014). Transnational Parenting and the Emergence of 'Diaspora Orphans' in Zimbabwe. African Diaspora, 7(1), 114-138.

[14] Lam, T., Ee, M., Anh, H. L., \& Yeoh, B. S. (2013). Securing a better living environment for left-behind children: implications and challenges for policies. Asian and Pacific Migration Journal, 22(3), 421- 445.

[15] Meyerhoefer, C. D., \& Chen, C. J. (2011). The effect of parental labour migration on children's educational progress in rural China. Review of Economics of the Household, 9(3), 379-396.

[16] UNICEF. (2006). The Situation of Children Left Behind by Migrating Parents. Moldova, UNICEF.

[17] Wilkinson, R. B. (2004). The role of parental and peer attachment in the psychological health and selfesteem of adolescents. Journal of Youth and Adolescence, 33(6), 479-493.

[18] UNICEF. (2006). The state of the world's children 2007: Women and children: The double dividend of gender equality (Vol. 7). UNICEF.

[19] UNICEF. (2011). Impact of labour migration on "children left behind" in Tajikistan. UNICEF Publication: Dushanbe, Tajikistan.

[20] Zimbabwe National Statistics (ZIMSTAT) (2014) Multiple Indicator Cluster Survey 2014, Key Findings. ZIMSTAT, Harare, Zimbabwe. URL: http://www.childinfo.org/files/Zimbabwe_2014 KFR.pdf

Citation: Pamela Chakombera, Augustine KudakwasheMubika. "A Comparative Analysis on the Social Wellbeing of Adolescents with Parents in the Diaspora and those with Parents in the Home Country. A Case Study of Adolescents at Nemakonde High School: Mashonaland West Region, Zimbabwe". International Journal of Humanities Social Sciences and Education (IJHSSE), vol 5, no. 2, 2018, pp. 35-42 doi: http://dx.doi.org/10.20431/2349-0381.0502005.

Copyright: (C) 2018 Authors. This is an open-access article distributed under the terms of the Creative Commons Attribution License, which permits unrestricted use, distribution, and reproduction in any medium, provided the original author and source are credited. 